\title{
Do celebrity endorsements matter? Observational study of BRCA gene testing and mastectomy rates after Angelina Jolie's New York Times editorial
}

\author{
Sunita Desai, ${ }^{1}$ Anupam B Jena ${ }^{1,2,3}$
}

1Department of Health Care Policy, Harvard Medical School, 180 Longwood Ave, Boston, MA 02115, USA

2Department of Medicine, Massachusetts General Hospital, Boston, MA, USA ${ }^{3}$ National Bureau of Economic Research, Cambridge, MA, USA Correspondence to: A B Jena jena@hcp.med.harvard.edu Additional material is published online only. To view please visit the journal online.

Cite this as: $B M / 2016 ; 355: i 6357$ http://dx.doi.org/10.1136/bmj.6357 Accepted: 16 November 2016

\section{ABSTRACT}

OBJECTIVE

To examine the effect on BRCA testing and mastectomy rates of a widely viewed 2013 New York Times editorial by public figure Angelina Jolie that endorsed BRCA testing and announced Jolie's decision to undergo preventive mastectomy.

DESIGN

Observational study with difference-in-difference analysis.

SETTING

Commercially insured US population.

\section{PARTICIPANTS}

Women aged 18-64 years with claims in the Truven MarketScan commercial claims database $(n=9532836)$.

\section{MAIN OUTCOME MEASURES}

Changes in BRCA testing rates in the 15 business days before versus after 14 May 2013 (editorial date) compared with the change in the same period in 2012; mastectomy rates in the months before and after publication, both overall and within 60 days of BRCA testing among women who were tested; national estimates of incremental tests and expenditures associated with Jolie's article in the 15 days after publication.

RESULTS

Daily BRCA test rates increased immediately after the 2013 editorial, from 0.71 tests/100 000 women in the 15 business days before to 1.13 tests/100 000 women in the 15 business days after publication. In comparison, daily test rates were similar in the same period in $2012(0.58 / 100000$ women in the 15 business days before 14 May versus $0.55 / 100000$

\section{WHAT IS ALREADY KNOWN ON THIS TOPIC}

Celebrity endorsements for health related matters such as preventive screening, fad diets, and supplements are ubiquitous

Evidence on whether celebrity endorsements actually affect health related behaviours remains limited

\section{WHAT THIS STUDY ADDS}

This study analysed the effect of an editorial on BRCA gene testing by Angelina Jolie on rates of BRCA testing and mastectomy in a large US population

A $64 \%$ increase in BRCA testing rates occurred in the 15 business days after the editorial was published, but with no increase in mastectomy rates in the following months

Celebrity announcements can influence use of healthcare services, but they may not effectively target the subpopulation at greatest risk for the underlying condition women in the 15 business days after), implying a difference-in-difference absolute daily increase of 0.45 tests $/ 100000$ women or a $64 \%$ relative increase $(P<0.001)$. The editorial was associated with an estimated increase of 4500 BRCA tests and $\$ 13.5 \mathrm{~m}$ ( $110.8 \mathrm{~m}$; €12.8) expenditure nationally among commercially insured adult women in those 15 days. Increased BRCA testing rates were sustained throughout 2013. Overall mastectomy rates remained unchanged in the months after publication, but 60 day mastectomy rates among women who had a BRCA test fell from $10 \%$ in the months before publication to $7 \%$ in the months after publication, suggesting that women who underwent tests as a result of to the editorial had a lower pre-test probability of having the BRCA mutation than women tested before the editorial.

\section{CONCLUSIONS}

Celebrity endorsements can have a large and immediate effect on use of health services. Such announcements can be a low cost means of reaching a broad audience quickly, but they may not effectively target the subpopulations that are most at risk for the relevant underlying condition.

\section{Introduction}

Celebrity endorsements of healthcare products and behaviours are ubiquitous. We studied the effect of a major announcement by actress Angelina Jolie, who in a 2013 New York Times editorial urged women to consider BRCA1/2 genetic testing and announced that she had undergone preventive mastectomy. ${ }^{1}$ The editorial is one of the most viewed health related articles in the social media age. ${ }^{23}$ To date, analyses of the editorial's effects have been limited to showing greater testing or referrals in small and specific subpopulations. ${ }^{45}$ Using data from a large commercially insured US population, we analysed rates of BRCA testing and mastectomy before and after Jolie's editorial.

\section{Methods \\ Data}

Our study included women aged 18-64 years in the United States who were continuously enrolled in commercial insurance during 2012-13. Data came from the Truven MarketScan Analytics Commercial Claims and Encounters Database, which comprises de-identified health insurance claims for inpatient care, outpatient care, and prescription drugs for more than 50 million people covered by self insured employers and health plans. Details of this database have been published elsewhere. ${ }^{6}$ 


\section{Analysis}

We identified BRCA gene testing according to Current Procedural Terminology codes 81211-81217 in outpatient claims. ${ }^{5}$ We estimated changes in BRCA testing after the editorial by using an individual level difference-in-difference model that compared the change in probability of BRCA testing in the 15 business days before versus the 15 business days after 14 May with the change in the same period in 2012 (to account for potential seasonal trends). We selected this relatively narrow time window to attenuate concern that factors other than Jolie's editorial would confound our estimates. In a sensitivity analysis, however, we extended the time window to 30 days. Individual covariates included patient's age (1825, 26-35, 36-45, 46-55, and 56-64 years), US Census region of residence (Northeast, North Central, South, West, unknown), and health plan type (preferred provider organisation (PPO), health maintenance organisation, consumer directed health plan, or other). Monthly BRCA testing rates in 2013, adjusted for number of days in the month, were reported to examine longer term trends. We estimated short term changes in spending on BRCA testing nationally (see online appendix).

We also graphically analysed changes in mastectomy rates after Jolie's editorial to assess whether any additional BRCA gene testing led to subsequent preventive mastectomies. ${ }^{7}$ As our data did not contain modifier codes that would indicate whether a mastectomy was preventive, we calculated monthly mastectomy rates in the overall study population as well as rates in the 60, 90, and 180 days after the test among women who underwent BRCA testing in 2013. If women responded to Jolie's editorial with more intensive treatment choices, we would expect rates of mastectomies to increase in the months after publication of the editorial. We included 90 and 180 day follow-up periods to allow sufficient time for women testing positive for BRCA to undergo mastectomy.

\section{Patient involvement}

No patients were involved in setting the research question or the outcome measures, nor were they involved in

\begin{tabular}{|c|c|c|}
\hline & $\begin{array}{l}\text { Full sample } \\
(n=9532836)\end{array}$ & $\begin{array}{l}\text { Women who had BRCA } \\
\text { testing }(n=32945)\end{array}$ \\
\hline \multicolumn{3}{|l|}{ Age category, years } \\
\hline $18-25$ & $1427952(15)$ & $850(3)$ \\
\hline $26-35$ & $1503136(16)$ & $3674(11)$ \\
\hline $36-45$ & $2036895(21)$ & $9506(29)$ \\
\hline $46-55$ & $2546635(27)$ & $11751(36)$ \\
\hline $56-64$ & $2018218(21)$ & $7164(22)$ \\
\hline \multicolumn{3}{|l|}{ US Census region } \\
\hline Northeast & $2157935(23)$ & $7497(23)$ \\
\hline North Central & $1949966(20)$ & $6370(19)$ \\
\hline South & $3118836(33)$ & $10464(32)$ \\
\hline West & $2100345(22)$ & $7800(24)$ \\
\hline Unknown & $205754(2)$ & $814(2)$ \\
\hline \multicolumn{3}{|l|}{ Insurance plan type } \\
\hline Preferred provider organisation & $5555048(58)$ & $22049(67)$ \\
\hline Health maintenance organisation & $1179703(12)$ & $4151(13)$ \\
\hline Consumer directed health plan & $440786(5)$ & $1870(6)$ \\
\hline Other & $2033167(21)$ & $3496(11)$ \\
\hline
\end{tabular}

developing plans for the design or implementation of the study. No patients were asked to advise on interpretation or writing up of results. There are no plans to disseminate the results of the research to study participants or the relevant patient community.

\section{Results}

\section{Study population}

Our sample included 9532836 women, of whom 2546635 (27\%) were aged 46-55 and 2018218 (21\%) were aged 56-64 in 2012 (table 1). Additionally, 3118836 (33\%) women resided in the South, and 5555048 (58\%) were in PPO plans. During the study period, 32945 $(0.35 \%)$ women had a BRCA test. Women who had BRCA tests were somewhat older (BRCA tested, $36 \%$ of women aged 46-55 and 22\% aged 56-64; non-tested, $27 \%$ of women aged 46-55 and 21\% aged 56-64), more heavily represented in the West ( $24 \% v 22 \%$ ), and more likely to be covered by a PPO health plan (67\% v 58\%). Of 32945 women who had a BRCA test during 2012-13, almost half (15233) had the test in the 231 remaining days of the year after the Jolie editorial was published (14 May 2013), which represented less than a third of the two year study period. Characteristics of women who had the test before publication of the editorial compared with those who had the test after it are shown in appendix 1. Women were similar in most characteristics, except that those who had the test after the editorial were slightly more likely to be covered under a PPO plan $(70 \%$ v 64\%).

\section{Rates of BRCA testing}

Daily BRCA test rates increased immediately and sharply after publication of the editorial. Rates rose from 0.71 tests per 100000 women in the 15 business days before to 1.13 tests in the 15 business days after 14 May 2013. In comparison, daily BRCA test rates were relatively similar in the same period in 2012 (0.58 per 100000 women in the 15 business days before 14 May versus 0.55 tests per 100000 in the 15 business days after) (fig 1). This corresponds to an adjusted difference-in-difference absolute daily increase of 0.45 tests per 100000 women or a $64 \%$ relative increase

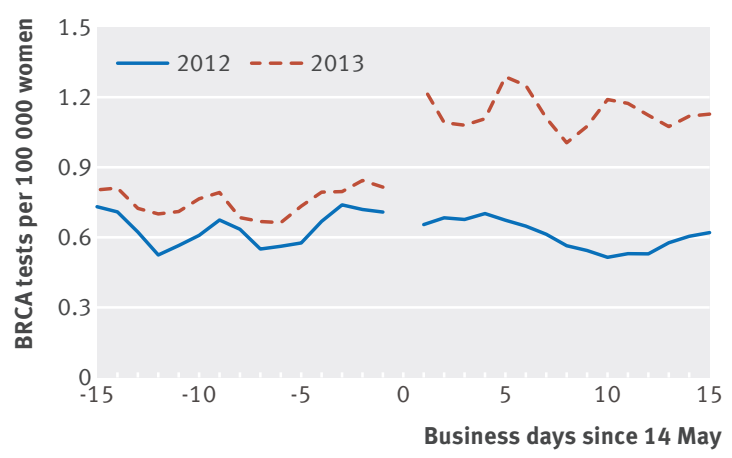

Fig 1 Daily BRCA test rates in 15 business days before and after 14 May 2013 Jolie editorial versus control period in 2012. BRCA tests were identified with Current Procedural Terminology codes 81211-81217. Figure shows three day moving average of testing rate. Rates in 2012 are shown as control to account for seasonal trends 


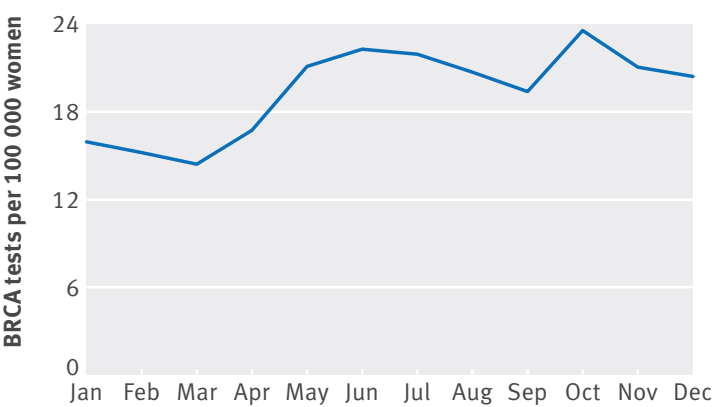

Month

Fig 2 | Monthly BRCA test rates before and after May 2013 Jolie editorial, adjusted for days in month. Rates for 2012 are not shown because coding changes implemented in early 2012 limit ability to accurately identify rates of testing in first three months of 2012

$(\mathrm{P}<0.001)$. Using a 30 day window, we estimated a difference-in-difference relative increase in BRCA testing rates of 52\% (appendix 2).

Increases in BRCA testing persisted to the end of our study period (fig 2). Average monthly test rates increased from 15.6 tests per 100000 women in months January to April 2013 to 21.3 tests per 100000 women during May to December 2013, a relative monthly increase of $37 \%$. Nationally, our results imply 4500 additional BRCA tests and more than $\$ 13.5 \mathrm{~m}$ (£10.8m; $€ 12.8$ ) in incremental expenditures on BRCA tests in the 15 business days after the editorial among commercially insured women aged 18-64 (appendix 3).

We saw no increase in mastectomy rates in the overall population, with an average of seven mastectomies a month per 100000 women during January to April as well as during May to December 2013 (fig 3). Moreover, among women who had BRCA tests, 60 day monthly mastectomy rates decreased from on average 10\% during January to April 2013 to 7\% during May to December 2013 (fig 4), further suggesting that incremental BRCA tests obtained as a result of the Jolie editorial did not yield additional BRCA positive mutations that might warrant preventive mastectomy. Ninety and 180 day monthly mastectomy rates (post-BRCA testing) suggested a similar pattern.

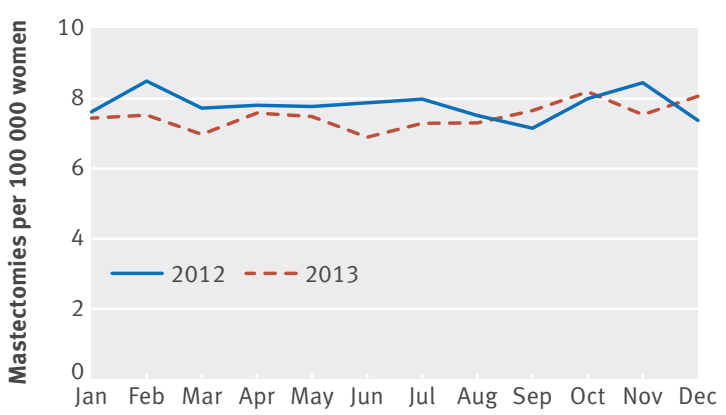

Month

Fig 3 | Monthly mastectomy rates before and after May 2013 Jolie editorial versus control period in 2012, adjusted for length of month. Rates for 2012 are shown to serve as control to account for seasonal trends

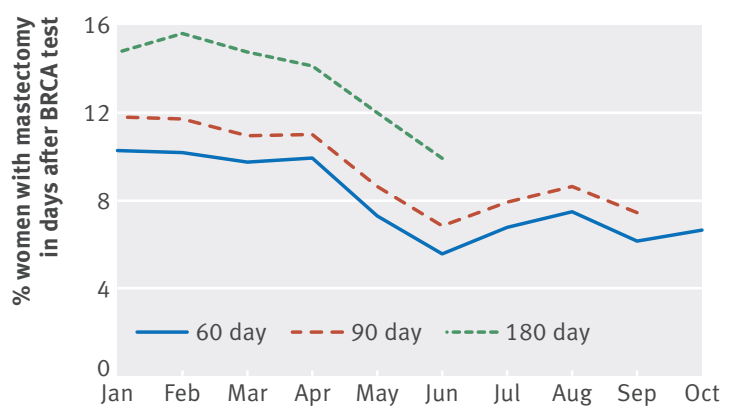

Fig $4 \mid 60,90$, and 180 day monthly mastectomy rates among women who had BRCA test before and after May 2013 Jolie editorial. For each data point, denominator is number of women who had BRCA gene test during month and numerator is number of women who had mastectomy in 60 (or 90 or 180) days after BRCA gene test. Rates for 2012 are not shown because coding changes implemented in early 2012 limit ability to accurately identify rates of BRCA gene testing in first three months of 2012

\section{Discussion}

We observed a large and immediate increase in BRCA testing among commercially insured women aged 18-64 years in the United States after Angelina Jolie's editorial. Our findings illustrate that well delivered announcements by high profile figures may be a low cost and effective means to influencing healthcare decision making, particularly in this social media age.

However, both stable overall mastectomy rates and decreased mastectomy rates among women who had a BRCA test after the editorial suggest that additional BRCA testing induced by the editorial probably did not identify new BRCA mutations requiring preventive mastectomy. This may suggest that incremental tests performed had a lower pre-test probability of being positive than tests done before the editorial or that additional women identified as having a BRCA mutation after the editorial were less likely to undergo preventive mastectomy. This also suggests that celebrity announcements can reach a broad audience but may not effectively target the population that would benefit most from the test, in this case women with a family history of breast, ovarian, fallopian tube, or peritoneal cancer, as advised by the US Preventive Services Task Force. ${ }^{8}$

\section{Limitations of study}

Because we did not observe test results, we did not measure benefits associated with knowing one's BRCA status such as peace of mind or increased vigilance after learning one's risk factors. Moreover, as our data did not allow us to identify preventive mastectomies, preventive mastectomies among women who tested positive for the BRCA mutation may have increased after Jolie's editorial even though overall mastectomy rates remained steady. Moreover, rates of mastectomy among women who tested positive for the BRCA mutation could have increased after the time captured by our study period. ${ }^{910}$ Finally, although our study population was more general than that of previous studies, certain 
populations such as Medicare enrolees were not represented.

\section{Conclusions}

We found an immediate increase in BRCA testing rates after Angelina Jolie's breast cancer editorial in the New York Times but no change in overall mastectomy rates and a decrease in mastectomy rates among women who had the BRCA test. Celebrity announcements in the social media age can raise awareness and use of preventive care by a large and broad audience, although their ability to target subpopulations of interest may be limited.

Contributors: Both authors contributed to the design and conduct of the study; data collection and management; analysis and interpretation of the data; and preparation, review, or approval of the manuscript. $A B$ J is the guarantor.

Funding: This research was supported by a grant from the Office of the Director, National Institutes of Health (AB): NIH early independence award; grant 1DP50D017897-01) and the Marshall J Seidman fellowship at Harvard Medical School (SD). Study sponsors were not involved in study design, data interpretation, writing, or the decision to submit the article for publication.

Competing interests: All authors have completed the ICMJE uniform disclosure form at www.icmje.org/coi_disclosure.pdf (available on request from the corresponding author) and declare: support provided by grants from the Office of the Director, National Institutes of Health, and the Marshall J Seidman fellowship at Harvard Medical School; AB has received consulting fees unrelated to this work from Pfizer, Hill Rom Services, Bristol Myers Squibb, Novartis Pharmaceuticals, Vertex Pharmaceuticals, and Precision Health Economics, a company providing consulting services to the life sciences industry; no other relationships or activities that could appear to have influenced the submitted work.

Ethical approval: The study was exempted from review by the Institutional Review Board at Harvard Medical School.

Transparency statement: The lead author affirms that this manuscript is an honest, accurate, and transparent account of the study being reported; that no important aspects of the study have been omitted; and that any discrepancies from the study as planned (and, if relevant, registered) have been explained.

Data sharing: no additional data available.

This is an Open Access article distributed in accordance with the Creative Commons Attribution Non Commercial (CC BY-NC 3.0) license, which permits others to distribute, remix, adapt, build upon this work non-commercially, and license their derivative works on different terms, provided the original work is properly cited and the use is non-commercial. See: http://creativecommons.org/licenses/ by-nc/3.0/.

1 Jolie A. My medical choice. New York Times, May 14, 2013 (available at http://www.nytimes.com/2013/05/14/opinion/ my-medical-choice.html).

2 Juthe RH, Zaharchuk A, Wang C. Celebrity disclosures and information seeking: the case of Angelina Jolie. Genet Med 2015;17:545-53. doi:10.1038/gim.2014.141

3 The New York Times's most visited content of 2013. 2014. http://www. nytco.com/

the-new-york-timess-most-visited-content-of-2013/?smid=tw-share.

4 Evans DG, Barwell J, Eccles DM, et al. FH02 Study Group RGC teams. The Angelina Jolie effect: how high celebrity profile can have a major impact on provision of cancer related services. Breast Cancer Res 2014:16:442 doi:10.1186/s13058-014-0442-6.

5 Kehl KL, Shen C, Litton JK, Arun B, Giordano SH. Rates of BRCA1/2 mutation testing among young survivors of breast cancer. Breast Cancer Res Treat 2016:155:165-73 doi:10.1007/s10549-015-3658-y.

6 Hansen LG, Chang MS. Health research data for the real world: the MarketScan databases. Truven Health Analytics, 2011.

7 Jagsi R, Jiang J, Momoh AO, et al. Complications after mastectomy and immediate breast reconstruction for breast cancer: a claims-based analysis. Ann Surg 2016;263:219-27. doi:10.1097/ SLA.0000000000001177.

8 Moyer VA. U.S. Preventive Services Task Force. Risk assessment, genetic counseling, and genetic testing for BRCA-related cancer in women: U.S. Preventive Services Task Force recommendation statement. Ann Intern Med 2014:160:271-81.

9 Evans DG, Wisely J, Clancy T, et al. Longer term effects of the Angelina Jolie effect: increased risk-reducing mastectomy rates in BRCA carriers and other high-risk women. Breast Cancer Res 2015;17:143. doi:10.1186/s13058-015-0650-8.

10 Malcolm CM, Javed MU, Nguyen D. Has the Angelina Jolie effect led to an increase in risk reducing mastectomy and breast reconstruction in Wales: A retrospective, single centre cohort study. I Plast Reconstr Aesthet Surg 2016;69:288-9. doi:10.1016/j.bjps.2015.10.018. 